\title{
Bank Supports the Field of New and Old Kinetic Energy Conversion and Research on Innovative Strategies
}

\author{
Baojing Zhou, Ying Zheng, Chunmin Ma \\ Shandong Vocational College of Science \& Technology, Weifang, Shandong, 261053
}

Keywords: Innovative Strategies, Kinetic Energy Conversion, New and Old Kinetic Energy

\begin{abstract}
This paper analyzes the connotation and mode of the new and old kinetic energy conversion, and then analyzes the dynamic evolution of the new and old kinetic energy conversion from the two-dimensional perspective of technical efficiency and technological progress. The transformation of new and old kinetic energy includes the focus of the four levels of factors, enterprises, industry and society. The transformation of old and new kinetic energy exists from the government-led to the government guidance, from the economic field to the social field, from the key demonstration to the comprehensive promotion, from the factor-driven to the innovation-driven, and from the gradual innovation to the subversive innovation.
\end{abstract}

\section{Introduction}

Since the reform and opening up in 1978, the Chinese economy has achieved a high-speed, sustained and steady development for 40 years, and the economy has moved to the second place in the world. The per capita GDP has risen from 190 US dollars in 1978 to 2016. 8,000 US dollars, into the ranks of middle-income countries, has become a great miracle in the history of world economic development. The reform and opening up has brought about a great filling of social material, and it has also transformed the main contradictions of society from "the contradiction between the growing material and cultural life needs of the people and the backward social production" to "the people's growing needs and imbalances in the better life." The contradiction between full development." Therefore, the main obstacle to the sustainable development of China is no longer the problem of insufficient social production, but how to achieve high-quality development. For example, the current stage of "sweeping goods abroad" has become more and more normal. Japanese toilets and rice cookers have been sought after by people at dozens of times and dozens of times, reflecting the high quality and high quality products and services. The pursuit. How to promote the transformation of old and new kinetic energy to achieve supply-side structural reforms, so as to better meet the high-quality and diverse needs of all people has become a major proposition in China's current theoretical research and practical exploration.

\section{Logical roots of new and old kinetic energy conversion}

On the one hand, from the perspective of the types, acquisition and utilization levels of production tools, the evolution of the world economy is the continuous evolution of production tools, and the process of realizing the continuous transformation of new and old kinetic energy. It is a new technical means and a new development concept for existing kinetic energy. Alternative process. In the early days of human society, stone tools obtained through accidental means such as picking up and striking became an important asset in production and life, but the acquisition of these tools has strong contingency and randomness, and the use efficiency is not high, and it is even less likely to achieve scale. Standardized production. People in the Iron Age have mastered the production process of iron tools, and the tools for production and life have become more diverse and standardized, and they have been able to achieve a certain level of large-scale production. The new kinetic energy (ironware) has realized the old kinetic energy (the stone tools) substitute. Since the beginning of the 20th century, the production tools that human beings can master have become more and more intelligent. The precision machine tools needed for industrialized large-scale 
production and intelligent production have already represented the unprecedented level of human mastery of production tools. For example, on behalf of the highest level of intelligent chip production process, the most important raw material used is wafers, and the raw materials for producing wafers are naturally ubiquitous silica, how to achieve from "sand" The transition from "wafer" to "chip" condenses the highest level of technology, the most advanced manufacturing processes and the most sophisticated production tools that human beings can learn for thousands of years. From the perspective of development at this stage, the extensive use of advanced production tools is not only the most important symbol of the conversion of old and new kinetic energy, but also a significant sign of economic evolution. As Marx pointed out, "the hand-grinding produces the society led by the feudal lord, steam mill What is produced is the society headed by industrial capitalists."

On the other hand, from the perspective of energy and factor acquisition and utilization, the evolution of the world economy is accompanied by increasing energy efficiency and utilization efficiency. When manpower is still the main source of power, the power that each person can provide can't even reach 1 horsepower. The "eight-lifting sedan" has become the standard configuration for the status of the government. In order to maintain a comfortable level of travel, a large number of Labor resources. Entering modern society, with the gradual use of coal, oil, solar energy, electricity and nuclear energy, the energy levels and scales that various convenient transportation vehicles can provide are rapidly increasing. For example, the power of aircraft carriers used by the military reaches 250,000 to 300,000. Horsepower, this is also the process of continuous conversion of old and new kinetic energy. From the point of view of the use of factors, the world economic growth also shows a gradual transition from factor-driven to innovation-driven. From the objective world to the natural resources to the innovative information resources, human dependence on traditional fossil resources is gradually reduced, and the important role of intangible elements such as knowledge, innovation, technology and information on economic growth is gradually emerging. From the perspective of the transformation of old and new kinetic energy, the transition from factor drive to innovation drive is also one of the realization paths of new and old kinetic energy conversion.

\section{The focus of the new and old kinetic energy conversion}

First, the transformation of old and new kinetic energy at the element level is the broad basis for the transformation of old and new kinetic energy. It mainly refers to the transformation from object to person, from tangible element to tangible element and intangible element. First, realize the transition from things to people. More and more attention is paid to human factors, and the transition from labor to human capital is realized. This is because knowledge, technology, patents, and information attached to people are important guarantees for determining the formation of new kinetic energy. Second, realize the transition from tangible elements to intangible elements. The role of land, capital, and labor in economic growth is steadily declining, while the intangible factors of production, such as knowledge, information, and data, are gradually emerging.

Second, the transformation of old and new kinetic energy at the element level needs to achieve a transition from factor-driven to innovation-driven. In order to promote the establishment of innovative countries and intensive societies, the transformation of old and new kinetic energy is the process of gradual improvement of total factor productivity. That is to say, the transformation of old and new kinetic energy at the element level will face a long-term transformation. The promotion of factors to economic growth is getting lower and lower, and the increase in total factor productivity due to other factors such as technology, management, organization, etc. will be more The bigger it is.

Third, the transformation of old and new kinetic energy at the factor level needs to deal with the relationship between emerging and traditional elements. In the process of promoting the transformation of old and new kinetic energy at the element level, it is still necessary to coordinate the relationship between emerging and traditional elements. Firmly grasp the innovation-driven "bull nose", effectively exert the contribution of innovation elements in the transformation of new 
and old kinetic energy, and constantly form a good situation in which innovative resources are collected and innovative elements are introduced, and the key elements of innovation are realized from the extension. The first engine role of quantitative growth to the development of intrinsic quality. The conversion of old and new kinetic energy at the element level does not depend solely on these more "advanced" factors of production. If the overall work only grasps this "bull nose", it will make a misunderstanding of "one leaf blindness, no Taishan". The innovative element is the "taste enhancer" that promotes the conversion of old and new kinetic energy into this dish, and still needs the "vegetable basket" of traditional elements. For example, in urban construction, blindly pursuing the gathering of high-level talents, dispelling and even shutting out ordinary workers, then who is providing a large number of supporting services for urban construction? Innovation elements cannot exist independently of traditional elements. The purpose of innovation is to achieve more efficient use of traditional elements. Therefore, it is necessary to make full use of the abundant labor, capital, natural resources, human capital, infrastructure and other advantages, rely more on the decisive role of the market "invisible hand" on resource allocation, and avoid the phenomenon of inefficient or even inefficient allocation of elements. Improve the utilization efficiency and allocation efficiency of traditional resources, and pay great attention to the coupling between these production factors to achieve a good situation of mutual benefit and symbiosis.

\section{Implementation path of new and old kinetic energy conversion}

The achievements since the reform and opening up have been to adhere to the gradual market-oriented reforms and actively handle the complex interaction between the government and the market. In the process of transforming old and new kinetic energy, it is necessary to strictly define the power boundary of "government-market" in light of specific situations, and move toward the development path from government-led to government-led transition. The government is by no means the dominant player in the conversion of old and new kinetic energy. This is because the government faces information asymmetry, it is difficult to obtain all the information and make the best choices. Therefore, relying on the government's choice may be inefficient or ineffective, and it also faces huge policy cost problems. The conversion of old and new kinetic energy can be achieved not through the actions of the government, but needs to include the active cooperation of people and things from all walks of life to promote the conversion of kinetic energy. As a vast system engineering, it is necessary to give play to the regulatory role of market mechanisms in resource allocation, enterprise entry and exit, and industrial development.

From the four levels of focus on the transformation of old and new kinetic energy, it can be seen that it includes not only the transformation of kinetic energy in the economic field, but also the spiritual and cultural changes at the entire social level. First of all, it is necessary to focus on the economic field, focusing on the economic level of factors, enterprises and industries, the transformation of old and new kinetic energy, which constitutes the main aspects of the transformation, but also the final destination of the conversion of old and new kinetic energy. The transformation of old and new kinetic energy in the economic field is an important strategy. There is not much experience to learn from in the early stage. It still needs to "cross the river by feeling the stones" and drive the transformation of old and new kinetic energy. The choice of development path should still be "big-minded and small-footed", and it is necessary to improve the utilization efficiency of micro-factors and the adoption of new factors. The transformation of new and old kinetic energy still needs to be implemented in enterprises, and the technical efficiency and technological progress of each enterprise. The progress of the development has become a river of

new kinetic energy for economic development. Secondly, in order to better promote the transformation of old and new kinetic energy in the economic field, it is still necessary to support the transformation of old and new kinetic energy in the social field, attach great importance to the transformation of old and new kinetic energy at the social level, and create favorable conditions conducive to the smooth operation of the economic field.

In order to effectively promote the smooth transition of old and new kinetic energy, comprehensive consideration of policy costs and policy effects, when promoting the transformation 
of new and old kinetic energy of enterprises, industries, regions, can not be comprehensive, otherwise it will face difficulties such as shortage of resources. Therefore, the feasible realistic development path should be promoted from the key demonstration. Relying on typical enterprises of various types, industries that need to focus on promoting transformation and upgrading, and key areas where transformation requirements are required to be prioritized, through policy support and top-level design, take the lead in making breakthroughs in key enterprises, industries and regions, and promote the formation of new and old kinetic energy conversion key demonstrations. A number of experiences, samples, and roads. For example, in the new and old kinetic energy conversion work in Shandong Province, it is the first to promote the development of "Jinan New and Old Kinetic Energy Conversion Pioneer Zone”. Through policy guidance, project security, and multi-party resources to participate in promoting the transformation of new and old kinetic energy, there is support and support. Condensing the development model is conducive to the formation of the "Jinan sample" and exporting experience. On this basis, it will gradually spread to more enterprises, industries and regions through the marketization of technology connections and technology diffusion, industrial linkages, regional technology spillovers, etc., and promote the expansion of new and old kinetic energy echelon. Therefore, it is possible to better balance the selection of the "cost-benefit" between the old and new kinetic energy conversion, and form a good situation in which the new and old kinetic energy conversion echelon evolves and develops layer by layer.

\section{Conclusion}

This paper explores the sources of innovation power of new and old kinetic energy transformation through the three levels of state, industry and enterprise, and analyzes the technological innovation as the core driving force, the service innovation as the key driving force and the system innovation as the guarantee to the transformation of old and new kinetic energy. mechanism. Under the background of innovation-driven development strategy, based on the connotation and development trend of the current new and old kinetic energy transformation, the corresponding strategy of accelerating the transformation of old and new kinetic energy is proposed.

\section{References}

[1] Zhang Zhuoyuan. Review of the marketization reform of China's economy for forty years [J]. Economics and Management Research, 2018(3): 3 - 15.

[2] Excellence, Zhang Wei. Distribution of Income in the Global Value Chain and "Tragic Growth"__Based on the Analysis of China's Textile and Apparel Industry [J]. China Industrial Economy, 2008 (7): 131 - 140.

[3] Liu Zhiwei, Zhang Jie. From the integration of global value chain to the construction of national value chain: strategic thinking of China's industrial upgrading [J]. Academic Monthly, 2009( 9) : 59 - 68.

[4] Qian Fangming. Research on the Upgrading Mechanism of Traditional Manufacturing Industry in the Yangtze River Delta Based on NVC [J]. Research Management, 2013( 4) : 74 - 78.

[5] Cai Wei, Wang Meiyan. China's income gap reality and middle income trap risk [J]. Journal of Renmin University of China, 2014( 3) : 2 - 7. 